\title{
The Experiences of Touch Therapies in Symptom Management of Rural and Regional Cancer Patients in Australia
}

Tamara Cadet, $\mathrm{PhD},{ }^{*}$ Cindy Davis, PhD, ${ }^{2}$ Patricia Wilson, MHealth, BCouns, RN, ${ }^{3}$ Jacinta Elks, $\mathrm{RN}^{4}$

'Dept. of Social Work, University of Pennsylvania, Philadelphia, PA, USA, ${ }^{2}$ Dept. of Social Work, University of the Sunshine Coast, Sippy Downs, QLD, ${ }^{3}$ Bloomhill Cancer Care Centre, Buderim, QLD, ${ }^{4}$ Sunshine Coast Hospital \& Health Services, Birtinya, QLD, Australia

Introduction: Cancer patients are increasingly combining touch therapies (e.g., remedial massage, lymphatic massage, and/or reflexology) with conventional treatments to deal with the impact of their cancer and treatments on their physical and mental well-being. To understand the impact of integrative oncology services on cancer patients, it is essential to explore the impact that various types of integrative oncology services have on cancer patients.

Aims: This paper presents cancer patients' experiences with touch therapies in a community-based cancer support center and to identify opportunities for better access to these practices and service provision in Australia.

Methods: A random selection of cancer patients $(n=36)$ receiving touch therapies at a rural/regional community cancer center completed mixed-methods mail surveys regarding the use of touch therapies, their satisfaction, and the impact on pain, fatigue, nausea and overall well-being.

Results: Findings indicated that these services helped manage both physical and emotional symptoms. Of the participants experiencing pain and fatigue, findings revealed that touch therapies assisted with pain in $90 \%$ of participants and with fatigue in $70 \%$.

Conclusion: Given the increased and continued use of touch therapies by individuals with cancer, cancer centers should consider establishing touch therapy services or provide referrals to touch therapy services that can assist with symptom management and improve quality care. By more clearly understanding the benefits of the different types of integrative oncology interventions, patients with cancer receive more tailored and effective interventions throughout of their cancer journey.
KEYWORDS: touch therapies; integrative oncology; complementary therapies; cancer; Australia; holistic care

\section{INTRODUCTION}

Cancer patients are increasingly combining complementary health-care interventions (e.g., acupuncture, massage therapy, and naturopathic medicine) with conventional treatments (e.g., chemotherapy and radiation). The integration of mind/body practices and natural products with conventional treatments is known as integrative oncology. ${ }^{(1)}$ Evidence suggests that half of patients with cancer utilize some integrative oncology. ${ }^{(1,2)}$ Specifically, Mao and colleagues indicated that more than $65 \%$ of U.S. cancer survivors had used integrative oncology to assist with pain management, insomnia, psychological distress, gaining a sense of control, symptom management, and noted the desire to utilize non-traditional therapies to treat symptoms or psychosocial needs. (3) Integrative oncology is considered a part of supportive cancer care.(4)

In Australia, where there were an estimated 150,000 cancer patients in 2020, research suggests that approximately $17 \%$ $87 \%$ of cancer patients have used at least one form of integrative oncology practices during their cancer treatment. $(5,6)$ The degree of range is due to variety in sampling, different study designs, what is considered "integrative oncology", and non-disclosure of use reporting by patients. (7) Findings from a systematic review indicated that of the 124 Australian hospitals listed as having an oncology department, only $28 \%$ of hospitals provided a referral to a integrative oncology care program. (8) Findings also revealed that less than $10 \%$ of these 
hospitals providing cancer care had incorporated integrative oncology as part of their services. ${ }^{(8)}$ Given the growing number of patients with cancer seeking integrative practices, this systematic review by Lim et at. documents the gap of service provision within the hospital setting. (8) Similarly, Smith and colleagues reported that only one-fourth of cancer centers across Australia had integrative oncology services that provided these types of programs to cancer patients, and there are even fewer community-based organizations providing these types of services. (9) None of the Australian community-based cancer services receive significant government funding. ${ }^{(10)}$

To understand the impact of integrative oncology services on cancer patients, it is important to begin to explore the impact that various types of integrative oncology services have on cancer patients. Research on touch therapies with cancer patients in Australia is limited, but studies conducted on these therapies have shown to have a positive impact on physical and emotional well-being. $(9,11)$ Touch therapies involve the use of the hands-on or near the body to assist with healing. A systematic review of touch therapies on various health issues and cancer patients found that these therapies positively affect pain and emotional well-being, but noted that more research needs to be conducted in this area. ${ }^{12,13)}$ Further, evidence suggests that an estimated $15 \%-20 \%$ of adult cancer survivors in Australia use massage therapy, and 3\%-7\% use other manual or touch therapies such as osteopathy, chiropractic, reflexology, or Reiki. ${ }^{(14,15)}$ In an Australian study of touch therapies with cancer patients, Sey and Hunter found a lack of available highquality massage services that patients reported that benefits of massage extended beyond symptomatic relief, and that there are significant logistical barriers to these types of services (e.g., financial, qualified practitioners). (16)

The current paper aims to explore and share the experiences of rural and regional patients with cancer with touch therapies in a community-based cancer center with the goal of collecting data to support the development of these opportunities in other cancer centers to provide better access to these practices and service provision. For purposes of the current study touch therapies were defined as remedial massage, lymphatic massage, and/or reflexology.
The study received ethical approval, and all participants provided informed consent.

\section{METHODS}

Bloomhill Cancer Care Center (Buderim, Queensland, Australia) is a non-government-funded community-based service that provides an integrated holistic care model.(17) The Center supports people of all ages in a rural/regional area of Queensland to live well with cancer. It aims to enhance the quality of life for people living withand beyond-cancer through practical, physical, and emotional support, utilizing education and awareness. The professional team at Bloomhill consists of nursing and allied health practitioners who work closely with clients' general practitioners, cancer specialists, nursing services, and other health-care providers to create a network of care for their patients. Services include nursing services, individual and group counselling, lymphoedema management, and complementary services (e.g., touch therapies, acupuncture, meditation, mindfulness, and yoga). All the staff providing touch therapy services are qualified therapists with a minimum of a Diploma of Massage Therapy or Diploma of Reflexology, as well as post-qualifications with additional training in oncology massage, and are full members of an appropriate professional association (e.g., Association of Massage Therapists). Frequency of therapies varies from once only to regular weekly or monthly 50-minute sessions, depending on the client's needs. In order to prevent any bias in the data collection, none of the professional team at Bloomhill was involved in the data collection or research for the current study.

A randomly generated cohort of 100 clients who had received touch therapies within a three-month period at BCC were invited to participate in a mail survey; 36 individuals returned completed surveys. A response rate of $36 \%$ is consistent for surveys of this nature, with ranges generally between $25 \%$ to $30 \% .{ }^{(17)}$ All data were collected within a two-week period immediately following the three-months of touch therapies. The questionnaire, which was part of an overall quality improvement project, included both closed and open subjective questions from the participants' experiences about the services they utilized, their satisfaction, and the impact 
of touch therapies on participants' pain, fatigue, nausea, and overall well-being. Participants identified which touch therapies they had used by a checklist of the following: remedial massage, reflexology, lymphatic massage or a combination of these services. The questionnaire included closed questions with dichotomous responses (yes/no) for the outcome variables regarding their experiences of pain, fatigue, nausea, depression, anxiety, and general well-being. In addition, for those participants experiencing these physical and emotional issues, the questionnaire included closed questions with dichotomous outcome responses (helped/not helped) on the impact of each type of touch therapy that they used. Participants also shared open-ended responses about what they enjoyed most/least about the services they utilized, as well as their experiences with touch therapies.

\section{RESULTS}

As shown in Figure 1, 28\% of participants accessed remedial massage, 28\% lymphatic massage, $8 \%$ reflexology, and $36 \%$ accessed a combination of these therapies. Ninety percent of participants experiencing pain identified that touch therapies helped manage that pain. Nearly 70\% experiencing fatigue felt an improvement after accessing touch therapy. Less than 15\% experienced nausea and just over $20 \%$ of those reported a benefit from touch therapy. One participant expressed the impact of touch therapies on reducing physical symptoms by stating, "It took away my pain." and "[I was able to understand] the pain in the body and its effects physically, mentally, and emotionally on the individual." Participants also reported positive feelings from the touch therapists' acknowledgement of their pain. For example, one participant stated a primary benefit as: "Increased understanding of my problem with fluid (lymph) retention in my breast. Acknowledgement that I had a real problem."

Over 50\% of participants reported having depression and nearly $90 \%$ of those reported a benefit from a touch therapy service. About $54 \%$ of participants reported having anxiety and $89 \%$ of those

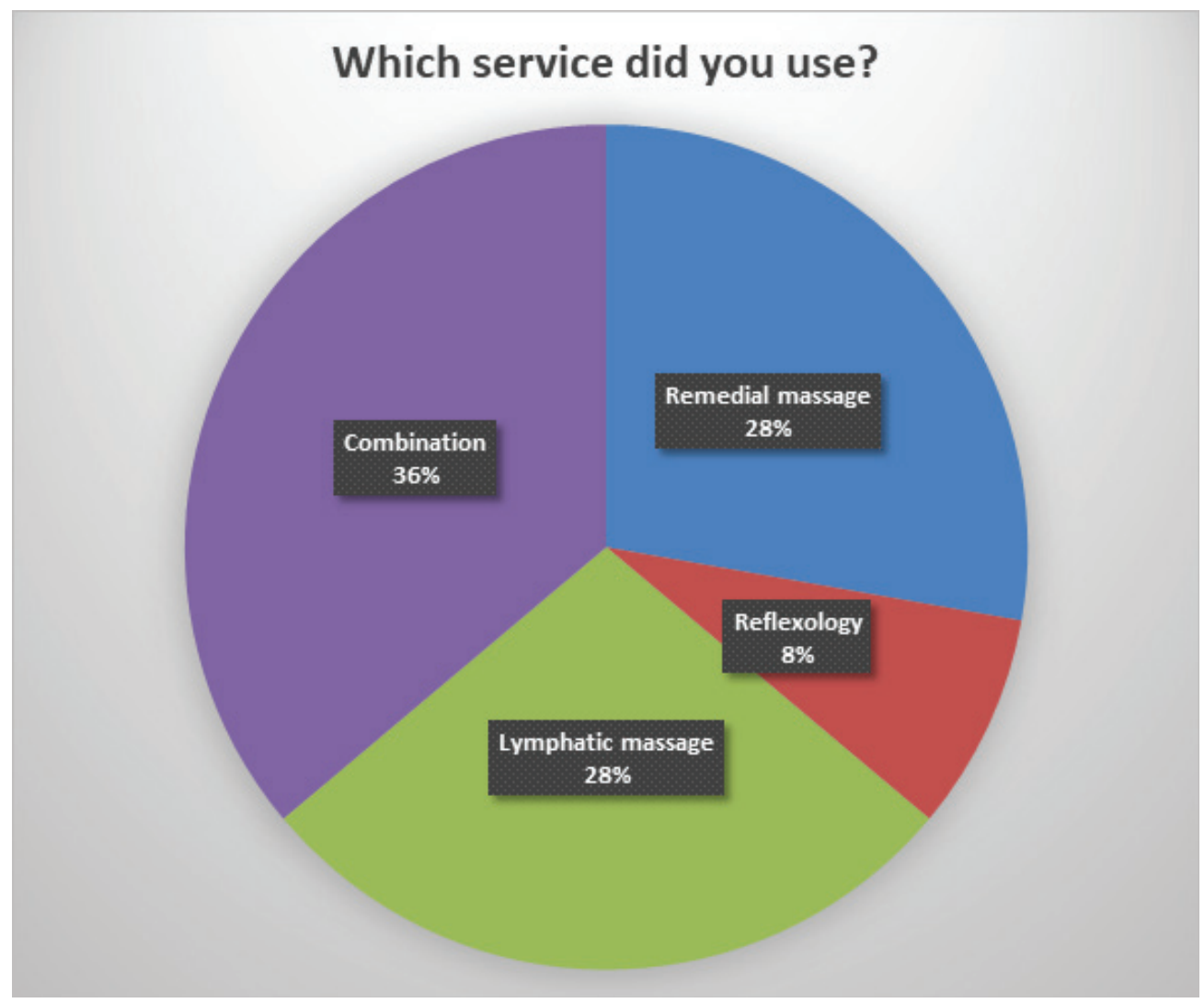

FIGURE 7. Touch therapies used by cancer patients. 
benefited from touch therapy with their anxiety. Participants described the impact of touch therapies on their emotional wellbeing as follows: "It helped my anxiety and to relax (I sleep well afterward)," and "Created a more relaxed feeling regarding my lymphoedema."

While one participant denied general well-being was an issue for them, all of the remaining clients reported well-being as a concern and stated that touch therapy benefited them in maintaining their wellbeing. For example, participants stated: "It has helped immensely with my ongoing well-being and has helped me understand self-management," and "Respite from the harsh and cold-hearted, disrespectful medical system." Another participant voiced how the touch therapies were able to assist in the understanding of the mindbody connection: "[The part I enjoyed most was] the understanding the ladies had of pain in the body, knowledge of cancer and its effects physically, mentally and emotionally on the individual." Participants also noted the importance of having the individualized touch therapies "tailored to my needs".

\section{DISCUSSION}

Although the overall results of participants using touch therapies are positive, there are some limitations that need to be considered. First, the small sample group in only one rural/regional community cancer center limited the generalizability of the results, and the methodology did not allow for pre/post effects of the interventions. Second, data were not collected on the number touch therapies sessions attended by each participant, so the quantity of touch therapies provided to participants is unknown. Lastly, Bloomhill provides services to patients with cancer at any point along the cancer trajectory; therefore, the study did not target a specific cancer stage (e.g., during adjunct treatment) and no data were collected on participants' current stage along their cancer journey. Despite these limitations, the current findings support the importance of touch therapies for some cancer patients.

Although this study did not assess immigration and cultural influences, studies have shown that cultural factors are an important consideration in relation to touch therapies. (18) With the increasing immigration trends globally, the possibility of cultural influences related to touch therapies and other integrative oncology practices should be expected, and offers an area for future research.

Given the increased use of touch therapies, cancer centers should consider establishing touch therapy services or provide referrals to touch therapy services to assist in managing cancer symptoms. Touch therapies are not well-integrated into the health services for cancer patients in Australia, especially in rural and remote regions; they are often viewed as nonessential "luxury" treatments, and financial restraints are a significant barrier to service provision. ${ }^{(15)}$ Despite reports of relatively high use of integrative oncology, Australia is behind other western countries (e.g., US and UK) in providing access to integrative oncology via primary oncology treatment settings. $(14,19,20)$ This is surprising since cancer survivors in 2017 make up $4 \%$ of Australia's population (more than one million).(21) This number is expected to increase to 1.9 million by 2040. (22) Given these numbers, it is important that post-treatment therapies, such as those discussed in the study, are recognized as possible strategies that might impact positive patient's experience in post-cancer treatment care. $(23,24)$ Treating these issues not only improves patient's quality of life, but also their health outcomes. (25) Further research is needed with more sophisticated designs to assess the pre/post effects of touch therapies, as well as the effects of the results over time.

Health and allied health professionals are in a unique position to educate patients about integrative oncology and to assist in establishing programs and initiating referrals to available services. Many patients may not know how to access credible information and how to make informed treatment decisions, particularly regarding integrative oncology. Health and allied health professionals should be aware of the role that touch therapies and other integrative oncology services can play in patient's lives, and of the programs that provide integrative oncology models of care, including touch therapies-thus improving health outcomes for cancer patients.

Understanding the benefits of the different types of integrative oncology interventions can assist in more tailored and effective interventions for cancer patients 
throughout their cancer journey. Cancer care cannot consist of a 'one size fits all' approach; a variety of services is needed to supported cancer patients from diagnosis to end-of-life care.(26) This study demonstrates that rural/regional cancer patients report a difference in their physical and emotional well-being due to touch therapies, which can assist in improving equity of access to information and support for patients completing cancer treatment in the adjuvant setting. Given the increased demand for integrative oncology by cancer patients, health professionals and care coordinators can play a pivotal role to establish links with well-qualified integrative oncology providers in the community and, where possible, advocate to have more of these services available for patients, especially in rural and remote regions where services are limited. Further research is needed to support the role and effectiveness of integrative oncology in meeting the needs of cancer patients in Australia, as well as strategies to facilitate how to successfully and systematically integrate these practices into Australian cancer care. (19) Further research is also needed on the role that integrative oncology professionals play in referring cancer patients to other allied and medical professionals, to meet the physical and psychological concerns of cancer patients.

\section{CONFLICT OF INTEREST NOTIFICATION}

The authors declare there are no conflicts of interest.

\section{COPYRIGHT}

Published under the CreativeCommons Attribution-NonCommercial-NoDerivs 3.0 License.

\section{REFERENCES}

1. Seely DM, Weeks LC, Young S. A systematic review of integrative oncology programs. Curr Oncol. 2012;19(6):e436. 2. Bell RM. A review of complementary and alternative medicine practices among cancer survivors. Clin J Oncol Nurs. 2010;14(3).

3. Mao JJ, Palmer CS, Healy KE, Desai K, Amsterdam J. Complementary and alternative medicine use among cancer survivors: a population-based study. J Cancer Survivorship. 2011;5(1):8-17.
4. Deng GE, Latte-Naor S. Integrative Oncology: The Role of Complementary Medicine in Supportive Cancer Care. In: Olver I. (ed) The MASCC Textbook of Cancer Supportive Care and Survivorship. New York, NK: Springer, Cham; 2018. p. 145-161.

5. Australian Institute of Health and Welfare. Cancer Data Australia [Internet]. Canberra, Australia: The Institute; 2020 [cited 2021 April 25]. Available from: https://www.aihw.gov.au/reports/cancer/cancerdata-in-australia/contents/summary

6. Cancer Council Australia. Position Statement on Alternative and Complementary Therapies. Sydney, NSW: Cancer Council Australia;2015 [cited 2021 May 1]. Available from: https://wiki.cancer.org.au/policy/ Position_statement_-_Complementary_and_alternative_therapies

7. Jones E, Nissen L, McCarthy A, Steadman K, Windsor $C$. Exploring the use of complementary and alternative medicine in cancer patients. Integrat Cancer Ther. 2019;18:1534735419846986.

8. Lim E, Vardy JL, Oh B, Dhillon HM. Integration of complementary and alternative medicine into cancer-specific supportive care programs in Australia: a scoping study. Asia-Pacific J Clin Oncol. 2017;13(1):6-12.

9. Smith CA, Hunter J, Delaney GP, Ussher JM, Templeman K, Grant S, et al. . Integrative oncology and complementary medicine cancer services in Australia: findings from a national cross-sectional survey. BMC Complement Alt Med. 2018;18(1):289.

10. Blignault I, McDonnell L, Aspinall D, Yates R, Reath J. Beyond diagnosis and survivorship: findings from a mixed-methods study of a communitybased cancer support service. Austral J Prim Health. 2017;23(4):391-396.

11. Stringer J. Complementary therapies in patientcenterd and integrated cancer care. In: Velikova G, Fallowfield L, Younger J, Board RE, Selby P, editors. Problem Solving in Patient-Centerd and Integrated Cancer Care. Witney, UK: EBN Health; 2018, p. 83-86.

12. So PS, Jiang JY, Qin Y. Touch therapies for pain relief in adults. Cochrane Database System Rev.2008(4).

13. Tabatabaee A, Tafreshi MZ, Rassouli M, Aledavood SA, AlaviMajd H, Farahmand SK. Effect of therapeutic touch in patients with cancer: a literature review. Med Arch. 2016;70(2):142.

14. On B, Butow P, Mullan B, Beale P, Pavlakis N, Rosenthal D, et al. The use and perceived benefits resulting from the use of complementary and alternative medicine by cancer patients in Australia. Asia-Pacific J Clin Oncol. 2010;6(4):342-349.

15. Sullivan A, Gilbar P, Curtain C. Complementary and alternative medicine use in cancer patients in rural Australia. Integrat Cancer Ther. 2015;14(4):350-358.

16. Sey AK, Hunter J. Finding the value in oncology massage: a mixed-method study of cancer services and survivors in Australia. Adv Integrat Med. 2020;7(3):126-134. 
17. Cadet T, Davis C, Elks J, Wilson P. A holistic model of care to support those living with and beyond cancer. Healthcare. 2016;4(4):88.

18. Balneaves LG, Wong ME, Porcino AJ, Truant TL, Thorne SE, Wong ST. Complementary and alternative medicine (CAM) information and support needs of Chinese-speaking cancer patients. Support Care Cancer. 2018;26(12):4151-4159.

19. Grant SJ, Hunter J, Bensoussan A, Delaney GP. Guidance for establishing an integrative oncology service in the Australian healthcare setting-a discussion paper. Support Care Cancer. 2018;26(2):471-481.

20. Horneber M, Bueschel G, Dennert G, Less D, Ritter E, Zwahlen M. How many cancer patients use complementary and alternative medicine: a systematic review and metaanalysis. Integrat Cancer Ther. 2012;11(3):187-203.

21. Kinnane NA, Piper A, Wiley G, Nolte L, Evans J, Jefford M. Transforming cancer survivorship care: an Australian experience. Asia-Pacific J Oncol Nurs. 2017;4(2): 91-94.

22. Cancer Council Australia. Australians living with and beyond cancer in 2040. Sydney, Australia: The Council; 2018 [cited 2021 September 1]. Available from: https://www.cancer.org.au/assets/pdf/number-of-australians-living-with-or-beyond-cancer
23. Miller KD, Siegel RL, Lin CC, Mariotto AB, Kramer JL, Rowland JH, et al. Cancer treatment and survivorship statistics. 2016. CA: a Cancer J for Clinicians. 2016;66(4):271-289.

24. Jefford M, Ward AC, Lisy K, Lacey K, Emery JD, Glaser AW, et al. Patient-reported outcomes in cancer survivors: a population-wide cross-sectional study. Support Care Cancer. 2017;25(10):3171-3179.

25. Maguire R, Kotronoulas G, Simpson M, Paterson C. A systematic review of the supportive care needs of women living with and beyond cervical cancer. Gynecol Oncol. 2015;136(3):478-490.

26. Cadet TJ, Elks JT, Moore M, Davis C. Cancer survivorship: does one size fit all? J Nurs Health Sci. 2017;3(3):32-38.

Corresponding author: Tamara Cadet, PhD, School of Social Policy \& Practice, University of Pennsylvania, 3701 Locust Walk, Philadelphia, PA 19104, USA

E-mail: cadet@upenn.edu 